Check for updates

Cite this: RSC Adv., 2018, 8, 38903

\title{
Experimental study of dust deposition in dynamic granular filters
}

\begin{abstract}
Wenning Zhou, (D) ab Juan Ma, ${ }^{a}$ Guoliang Zeng ${ }^{a}$ and Baiqian Liu (D) *ab
The aim of the present study is to investigate the process of dust deposition and its effects on the filtration performance of dynamic granular filters. We proposed a new theoretical explanation about the model for dust cake formation and growth, especially for the compression model at higher filtration superficial velocities in dynamic granular filters. The thickness and porosity of dust cakes can be estimated by formulas. Then, the effects of cake formation and growth on filtration performance were examined. It is found that there is an optimum thickness of the cake at which the dynamic granular filter achieves excellent collection efficiency with low system resistance. Moreover, an increasing pattern of pressure drop with cake thickness under different filtration superficial velocities was observed. Experimental results show that the pressure drops across the filter system and dust cake increase exponentially with increasing filtration superficial velocity. An appropriate filtration superficial velocity should be considered to achieve optimum filtration performance in dynamic granular filters. It is expected that the results of this study could provide useful information on designing dynamic granular filters for removal of dust particulates in Integrated Gasification Combined-Cycle (IGCC) and Pressurized Fluidized-Bed Combustion (PFBC).
\end{abstract}

Received 5th September 2018 Accepted 6th November 2018

DOI: 10.1039/c8ra07411a

rsc.li/rsc-advances problem of large amount of maintenance work. ${ }^{6}$ As for wet dust collectors, they are usually vulnerable to corrosion and production of waste liquids and solids, causing secondary pollution. $^{7}$

The key components for gas-solid separation equipment are dust removal devices, especially for hot gas clean-up, which should be filtrated with efficiency, reliability, low resistance and low cost. Granular filters have a long history in separation technology, regarded as having the most potential in industrial use of granular material to separate particles from flue gas. ${ }^{\mathbf{8 - 1 1}}$ As granular material consists of inorganics such as silica sand, ceramics and the particles are made by refractories, granular filters can be adopted in hot gas cleaning such as IGCC and PFBC. ${ }^{12}$ So far, granular filters operating in fixed bed conditions have been applied in small industrial devices. However, the moving granular filter still remains in research labs and has not been widely applied in industry.

Zhang et al. ${ }^{\mathbf{1 3}}$ conducted lab-scale coal pyrolysis experiments on a moving granular filter. They claimed that a higher filter height, slower superficial gas velocity and smaller medium size are favourable to decrease the dust content in the pyrolysis volatiles of coal. Previous experiments have indicated that the collected dust particles accumulate on the free surface of granules and form a compact structure during the deep-bed filtration mode, which has a strong ability to trap fly ash, so that collection efficiency can be improved. ${ }^{\mathbf{1 4}}$ Hence, the structure of the granular bed and dust cake formation and growth play important roles in the filtration performances of granular
${ }^{a}$ School of Energy and Environmental Engineering, University of Science and Technology Beijing, Beijing 100083, China

${ }^{b}$ Beijing Key Laboratory of Energy Saving and Emission Reduction for Metallurgical Industry, University of Science and Technology Beijing, Beijing 100083, China. E-mail: liubq@ustb.edu.cn; Tel: +8610 62334891 
beds. Much research work has been done in this area on granular filters, including that by Rodon and Lee, ${ }^{\mathbf{1 5}}$ Otoom, ${ }^{\mathbf{1 6}}$ Chen and Hsiau, ${ }^{17}$ Qin and Pletcher, ${ }^{18}$ etc. Various filter structures and flow patterns of granular material have been proposed. Meanwhile, several researchers have reported their investigations on pressure drop, collection efficiency and porosity of dust cake during cake filtration in granular filters. ${ }^{19-21}$ The effects of dust properties, granular material properties, and structures of the filter on dust cake formation and collection efficiency of the filter have been examined. Choi ${ }^{22}$ concluded that the dust cake was compressed by former cake layers with drag forces of later-formed dust layers, which was based on the dust build up model proposed by Schmidt. $^{23}$ Moreover, Qin and Pletcher ${ }^{\mathbf{1 8}}$ proposed that two increasing patterns of pressure drop were caused by different deposit distributions, termed homogeneous and heterogeneous depositions, rather than different increasing mechanisms of pressure drop. Although much work has been carried out in this field, in-depth understanding of the mechanism of cake formation/growth and design principles of granular filters is still missing, which is essential to the collection efficiency, filter system resistance and further industrialization of moving granular filters. In our previous study, we proposed a novel design of moving granular filter, i.e., dynamic granular filter. ${ }^{24}$ Inspired by dam technique in irrigation works, the novel dynamic granular filter was designed with louvers and sublouvers as dams and downflow weirs, respectively. We proposed using the inertial number criterion, which guarantees that the granular materials are kept in dynamic condition, to design the structure and effectively reduce the stagnant zone of the dynamic granular filter. There are two types of structure for dynamic granular filters, vertical and inclined filters. In the present study, the experiments were conducted on an inclined filter.

As is known, the dust cake grows thicker with filtration time and the pressure drop across the cake increases. The deposition of dust cake greatly affects the performance of granular filter performance, as well as collection efficiency and energy consumption. Based on the newly designed dynamic granular filter, this study focused on the formation and growth of dust cake during filtration. A new theoretical explanation regarding the model of cake formation and growth was proposed. In addition, the effects of filtration superficial velocity on cake formation and growth and also the pressure drop of granular filter system were examined. It is hoped that this study could lay a foundation for the industrialization of this promising dust removal technology.

\section{Experimental section}

\section{Mechanism of dynamic granular filter}

In our previous study, a dynamic granular filter was proposed with the louver and sub-louver structure, which can form a layer of fast granular particle flow and reduce the stagnant zone. Therefore, the granular flow layer can deliver the dust cake on the gas-solid separation surface and the cake will not grow too strong. ${ }^{24}$ The schematic diagram of vertical dynamic granular

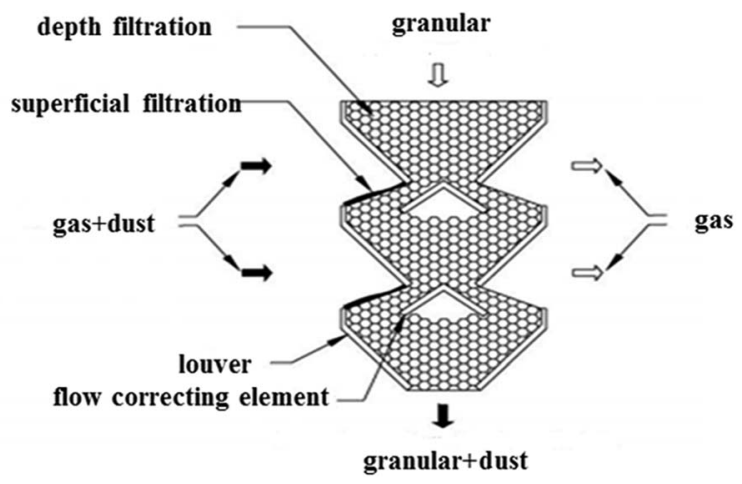

Fig. 1 Schematic diagram of vertical dynamic granular filter.

filter is shown in Fig. 1. There are a few factors affecting collection efficiency such as the physical properties of the filter material (filter material size, surface roughness, etc.), dust physical properties, gas flow field and other factors. In principle, several separate mechanisms could contribute to the filtration efficiency, including inertial impaction, diffusion, gravitational settling, interception, and electrostatic attraction. ${ }^{25,26}$ In dynamic granular filters, the dust particulates follow the curvilinear path of gas motion and tend to move along the gas streamlines until being deposited on the filter granules. The collection mechanisms mainly include inertial impaction and diffusion. $^{27}$

The following analyses are carried out for a case where the mechanisms of inertial impaction and diffusion dominate the filtration performance. For the inertial impaction filters, the Stokes number St is defined as ${ }^{28,29}$

$$
\mathrm{St}=C_{\mathrm{m}} \frac{\rho_{\mathrm{p}} d_{\mathrm{p}}{ }^{2}}{9 \mu d_{\mathrm{m}}} U
$$

where $C_{\mathrm{m}}$ is Cunningham's correction factor; $\rho_{\mathrm{p}}$ denotes the dust particle density; $d_{\mathrm{p}}$ is dust particle diameter; $d_{\mathrm{m}}$ is the average diameter of the filter granules; $\mu$ represents the viscosity of the gas and $U$ is the filtration superficial velocity. The kinetic energy of the dust particulates increases with increasing Stokes number due to the influence of filtration superficial velocity. Generally, the collection efficiency would exceed $90 \%$ when St > 0.01. In addition, for a very small size of dust particulates, Brownian diffusion plays a key role. The Peclet number Pe can be defined as ${ }^{30}$

$$
\mathrm{Pe}=\frac{3 \pi \mu d_{\mathrm{p}} d_{\mathrm{m}}}{C_{\mathrm{m}} K T} U
$$

where $K$ is the Boltzmann constant and $T$ is the absolute temperature. The collection efficiency could exceed $90 \%$ for $\mathrm{Pe}<$ 1000, which corresponds to particulates smaller than $0.1 \mu \mathrm{m}$. One can refer to our previous study for more details regarding the mechanism of the dynamic granular filter. ${ }^{24}$ In this study, Stokes and Peclet number analyses were used to ensure the design and working parameters of dynamic granular filter are in a logical situation, and thereby obtain optimum filtration performance. 


\section{Experimental apparatus and procedures}

When the dust laden gas reaches the surface of the granular layer, the dust particulates are intercepted, captured, and deposited on the surface of the filter granules to form a dust cake. Different from a normal granular filter, the dynamic granular filter was designed with the structure of retaining dam and overflow dam. The function of the retaining dam is to ensure that the filter granules fall without forming a particle stack induced by gravity and the aim of the overflow dam is to interrupt the force chain. Thus, the stagnant zone becomes active and the fast-moving granular layer delivers the collected dust particulates out of the filter. With the increase in the thickness of dust cake, the porosity of the cake decreases and the pressure drop of the filter system increases rapidly.

Fig. 2 illustrates the structure of the inclined dynamic granular filter used in the current experiments. All of the experiments of the present study are cold tests. Mung beans with particle sizes ranging from $3 \mathrm{~mm}$ to $5 \mathrm{~mm}$ and a density of $1300 \mathrm{~kg} \mathrm{~m}^{-3}$ were used as the filter granules. The dust particulates applied in the experiments were obtained from a $150 \mathrm{MW}$ circulating fluidized bed boiler. Fig. 3 shows the size distribution of dust particulates measured by Malvern Particle Size Analyzer. It can be seen from the figure that the peak is about $45.6 \mu \mathrm{m}$ at the dust laden gas inlet and $12.7 \mu \mathrm{m}$ at the outlet. It is evident that the dynamic granular filter has an excellent performance of trapping dust particulates. There are three pressure measuring points in each layer of the granular material, and the average value is taken as the filter system pressure drop. Main parameters and data used in the experiments are shown in Table 1.

The experiments are divided into three stages. First, we carry out tests on pressure drop of the filter granules under different superficial filtration velocities at free load condition, i.e. without

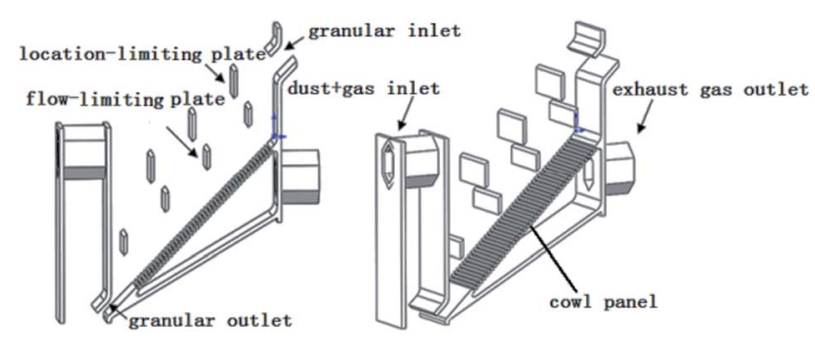

Fig. 2 Schematic diagram of inclined dynamic granular filter.

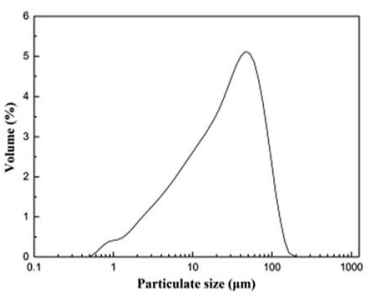

(a)

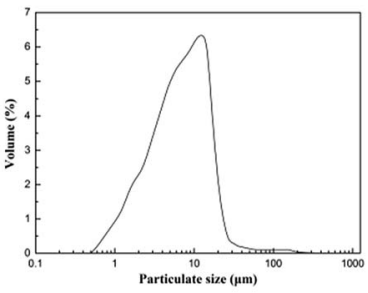

(b)
Fig. 3 Size distribution of dust particles at the (a) inlet and (b) outlet of experimental apparatus.
Table 1 Operating parameter and data in the experiments

\begin{tabular}{ll}
\hline Parameter & Data \\
\hline Density of dust particle $\left(\mathrm{kg} \mathrm{m}^{-3}\right)$ & 1550 \\
Filtration superficial velocity $\left(\mathrm{m} \mathrm{s}^{-1}\right)$ & $0.5,0.6,0.7$ \\
Flow rate of granular $\left(\mathrm{g} \mathrm{min} \mathrm{min}^{-1}\right)$ & 300 \\
Effective dust removal area on free surface $\left(\mathrm{m}^{2}\right)$ & 0.292 \\
Values of air flow $\left(\mathrm{m}^{3} \mathrm{~min}^{-1}\right)$ & 18 \\
Gas viscosity $(\mathrm{Pa} \mathrm{s})$ & $1.849 \times 10^{-5}$ \\
Concentration of dust particle $\left(\mathrm{g} \mathrm{m}^{-3}\right)$ & 2 \\
Diameter of granules $(\mu \mathrm{m})$ & 35
\end{tabular}

adding dust particulates into gas flow. The second stage operates at the fixed bed condition. The dust particulates are fed into gas flow by a screw feeder and an air fan. The filter granules are kept static to form a dust cake. The pressure drop of the filter starts to increase. After a certain period of time, the increase rate of pressure drop becomes smaller. The feeder for granules will be then opened and the fixed bed transfers to dynamic granular bed at the final stage. The dust particulates deposited on the cake are updated and delivered out of the filter. The cake thickness could be adjusted by the flow rate of filter material. The detailed diagram for the filter system can be found in our previous study. ${ }^{24}$

\section{Results and discussion}

\section{The three stages of filtering process and cake growth}

The process of filtering in dynamic granular bed also falls into three stages. In the first depth filtration stage, the capture of dust particulates occurs inside the filter and the dust particulates are retained between the filter granules. The second stage is referred as transition filtration stage. The captured dust particulates start to combine with filter granules to form dendrites which act as new collecting elements and the pressure drop starts to rise significantly. Finally, once a layer of dust cake has formed on the filter surface, the stage of surface filtration takes place, in which the filter cake takes on the main role of capturing dust particulates. Fig. 4 shows the initial free surface and dust cake formed at the gas inlet. The design of inclined dynamic granular filter, including the angle, distance and size of louvers, followed inertial number theory. ${ }^{24}$

The deposition and growth of dust cake at different filtration times in the current experiment are presented in Fig. 5. It is observed that the thickness of dust cake increases with the progress in filtration time. The final thickness and porosity of dust cake are related to the filtration superficial velocity and other factors, which will be examined in the next section.

\section{Determination of cake porosity and thickness}

As the strength of dust cake formed during filtration is relatively low, the cake can be easily disintegrated during handling or attempts to measure physical parameters. Moreover, the wide distribution of cake thickness makes the measurement of cake thickness very difficult. In this study, we proposed a theoretical formulation of cake thickness and porosity for the granular filter. 


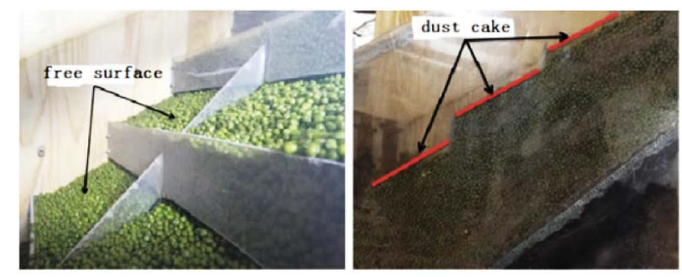

Fig. 4 The initial free surface and dust cake at the gas inlet.

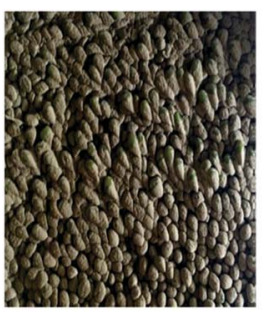

(a)

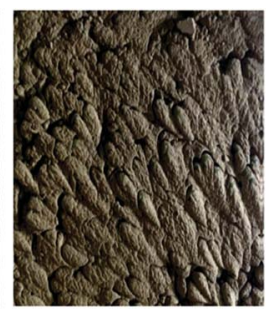

(b)

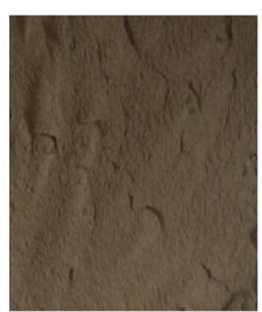

(c)
Fig. 5 The growth of dust cake on free surface after (a) 45 minutes; (b) 90 minutes; (c) 120 minutes.

In the experiments, pressure drop was measured by pressure values at three measuring points on the inlet and outlet surfaces of the gas. The average pressure drop can be determined by the equation

$$
\Delta P=\frac{\left(P_{\text {in } 1}-P_{\text {out } 1}\right)+\left(P_{\text {in } 2}-P_{\text {out } 2}\right)+\left(P_{\text {in } 3}-P_{\text {out } 3}\right)}{3}
$$

where $P_{\text {in } n}$ is the pressure value of inlet measured by the number of $n$ micro-pressure gauge at the inlet; $P_{\text {out } n}$ is the pressure value of outlet measured by the number of $n$ micropressure gauge at the outlet. $\Delta P$ represents the total pressure drop of the filter system, which should include pressure drop across granules and pressure drop across dust cake. Hence, the filter system pressure drop $\Delta P$ can be written as

$$
\Delta P=\Delta P_{\mathrm{F}}+\Delta P_{\mathrm{C}}
$$

where $\Delta P_{\mathrm{C}}$ is the pressure drop across the dust cake and $\Delta P_{\mathrm{F}}$ is the pressure drop of the granular filter, which can be obtained by measuring the pressure drop before dust particulates are fed to the filter. To study the pressure drop across the dust cake, it is necessary to utilize Ergun's equation in cake filtration, which can be expressed as $^{31}$

$$
\frac{\Delta P_{\mathrm{C}}}{L}=\frac{150 \mu}{d_{\mathrm{p}}{ }^{2}} \frac{(1-\varepsilon)^{2}}{\varepsilon^{3}} U+\frac{1.75 \rho_{\mathrm{g}}}{d_{\mathrm{p}}} \frac{U^{2}}{\varepsilon^{3}}
$$

where $L$ denotes the average thickness of the cake; $d_{\mathrm{p}}$ is the dust particulate diameter; $\mu$ is the gas viscosity; $\varepsilon$ is the porosity of the cake; $U$ is the filtration superficial velocity and $\rho_{\mathrm{g}}$ is the gas density. Meanwhile, the mass of dust deposited on the dynamic granular filter can be written as

$$
M=Q t=L A \rho_{\mathrm{p}}(1-\varepsilon)
$$

where $Q$ is the mass flow rate, $t$ is the filtration time, $A$ is the superficial area of the cake and $\rho_{\mathrm{p}}$ is the dust density. So there are two unknown parameters including the porosity $\varepsilon$ and thickness $L$. The remaining parameters are the physical properties of filter material, dust and gas, which can be obtained by experiment. Thus, the two unknown parameters, cake porosity and thickness, can be calculated by considering eqn (5) and (6).

\section{Pressure drop of dust cake and filter}

Besides collection efficiency, the pressure drop of dynamic granular filter also plays an important role in determining the energy consumption of the filter. The collection efficiency of dynamic granular filters has been examined in our previous study. Greater than 99\% collection efficiency indicates that dynamic granular filters could be a promising technology for the hot gas dust removal industry. ${ }^{24}$ In the present study, we mainly focus on the pressure drop of the filter and the dust cake. Fig. 6 shows the pressure drops of the filter system, i.e., granular and cake pressure drop, and granular pressure drop only varies with filtration superficial velocity. According to eqn (4), the pressure drop across the dust cake is the pressure drop across granules subtracted from the filter system pressure drop. It can be seen from this figure that both pressure drops increase exponentially with increasing filtration superficial velocity and the increase is more significant for the filter system. As expressed in Ergun's equation, filtration superficial velocity exponentially affects the pressure drop across the dust cake, which agrees with the experimental results in this study. As a matter of fact, due to the compression of dust cake being a complex microscopic process, the pressure drop across the dust cake increases with increasing cake thickness and filtration superficial velocity, but at a different scale.

Fig. 7 displays the pressure drop versus filtration time at different filtration superficial velocities. From this figure, it is observed that the total pressure drops at the beginning, i.e., pressure drop across filter granules only, are evidently different at different filtration superficial velocities. With the progress in filtration time, the total pressure drop across the filter and dust cake increases. Fig. 7b demonstrates the pressure drop across dust cake versus filtration time at different filtration superficial

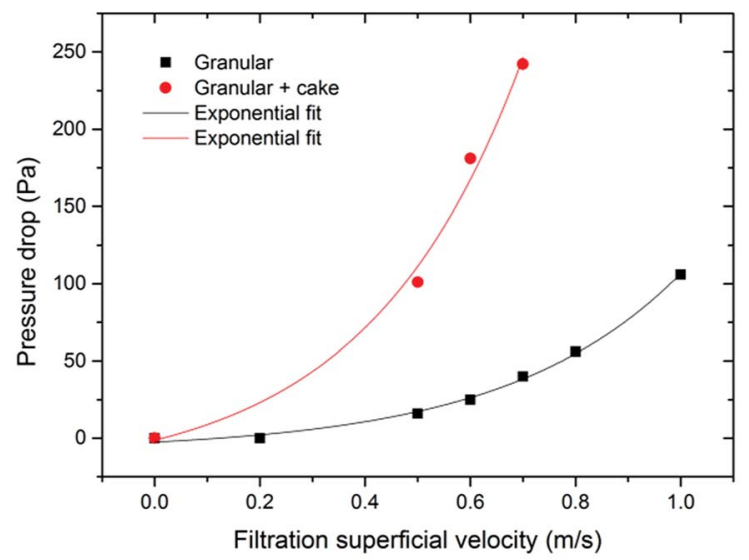

Fig. 6 Variation of pressure drop with filtration superficial velocity. 


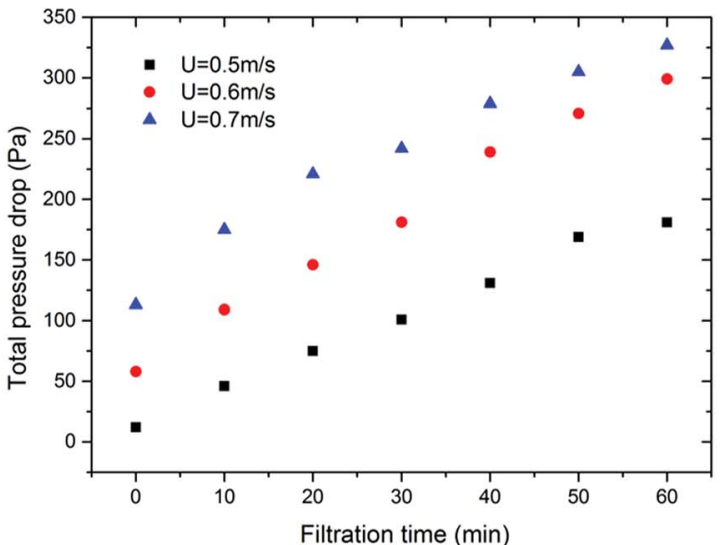

(a)

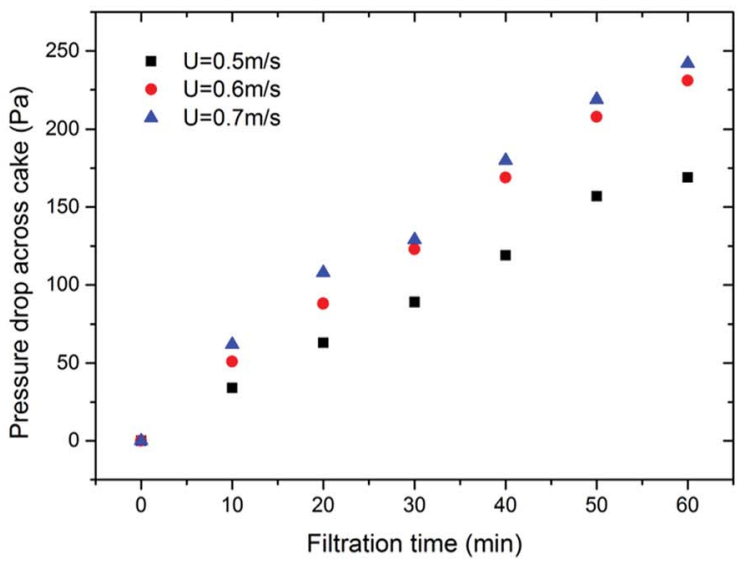

(b)

Fig. 7 Pressure drops versus filtration time at different filtration superficial velocities.

velocities. In general, the pressure drop across the dust cake increases with filtration time, but the pressure drop at smaller filtration superficial velocities increases relatively slowly. Similar results were reported in the study. ${ }^{32}$ This is due to the dust cake being compressed much harder at higher filtration superficial velocities, corresponding to smaller porosity, lower cake thickness and higher pressure drop of the filter. In other words, a higher filtration superficial velocity could increase the processing amount of dust laden gas, but this will also cause lower collection efficiency ${ }^{24}$ and consume more energy. A balanced consideration of the collection efficiency, energy consumption and processing amount is needed for dynamic granular filters in practical applications.

The relationship between cake thickness and pressure drop across cake is presented in Fig. 8. It is found that the increase in dust cake thickness causes linear growth of pressure drop, which can also be observed from eqn (5). Because the variation of porosity is tiny at fixed filtration superficial velocity, the inertial term of Ergun's equation is relatively small compared to the viscous term. Therefore, thickness of the dust cake is almost proportional to the pressure drop. In the case of the same thickness of dust cake, the higher the filtration superficial velocity, the larger the pressure drop it has. This is because the

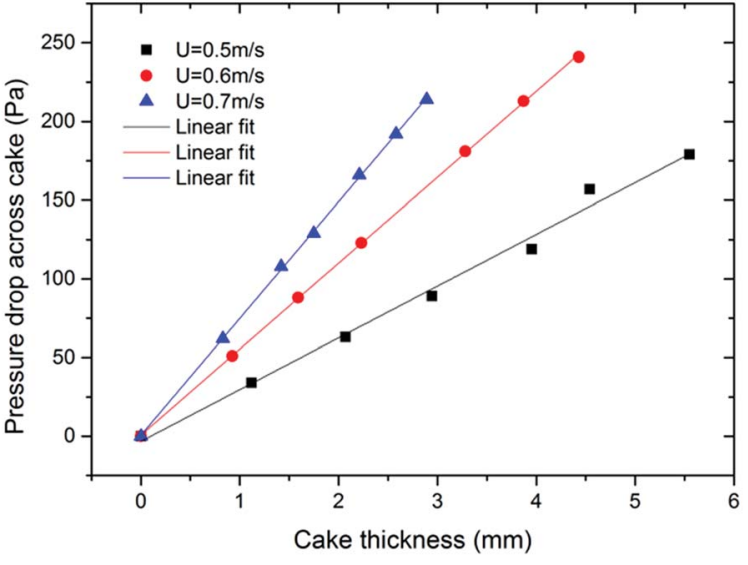

Fig. 8 The relationship between cake thickness and pressure drop across cake.

porosity decreases with a higher filtration superficial velocity, indicating that the cake is compressed more tightly. It can also be observed that the slope increases with increasing filtration superficial velocity, which means that the thickness is relatively thinner at a higher filtration superficial velocity. This phenomenon reflects that the compression of the dust cake is stronger and the porosity is smaller at higher filtration superficial velocity. In addition, dust laden gas has larger kinetic energy at a higher filtration superficial velocity. Thus, the layer of dust cake is compressed by the drag force caused by pressure drop until the drag force is close to the particle's maximum interparticle adhesion force and the friction angle between particulates. Then, the movement of dust particulates stops. Because dust particulates move along the direction of cake growth, the dust cake is compressed and cake porosity decreases. At higher pressure drop, the dust particulates keep moving instead of staying at the surface of the cake in a porous layer. Hence, the thickness of dust cake is relatively thinner and the increase of cake thickness is much slower.

Fig. 9 shows that the percentage of pressure drop across dust cake to filter system varies with filtration time. From this figure, it can be seen that the percentage increases rapidly during the

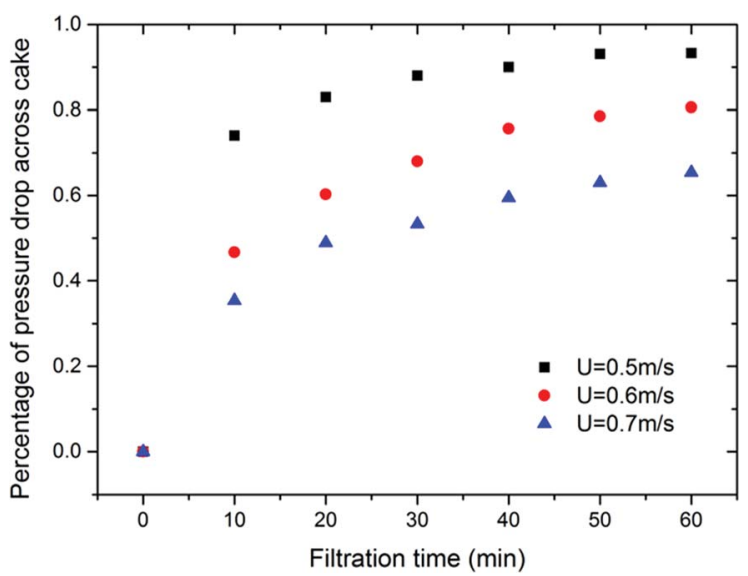

Fig. 9 Variation of percentage of pressure drop across dust cake with filtration time. 


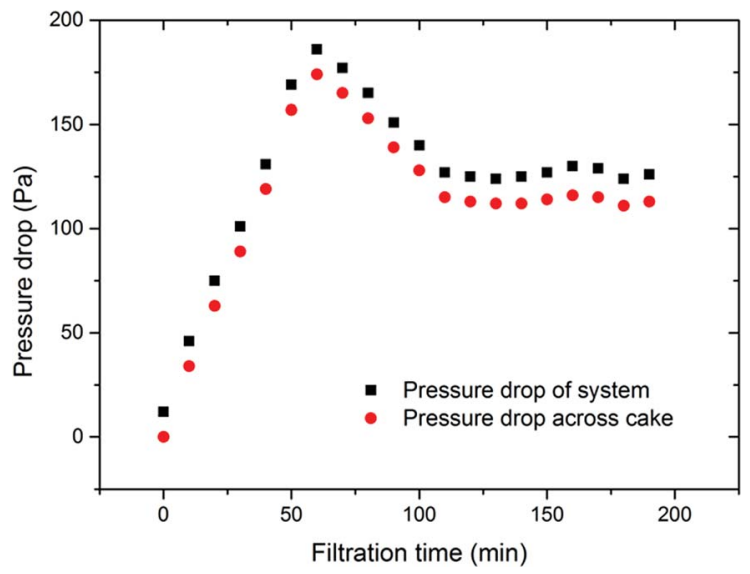

Fig. 10 Variation of pressure drop with filtration time, $U=0.5 \mathrm{~m} \mathrm{~s}^{-1}$.

initial 10-20 minutes while the dust cake is forming. After that, the increase in the percentage becomes more slower for different filtration superficial velocities. Further, the increase tends to be gentle and remains almost constant after about 50 minutes. The final pressure drop percentage of dust cake differs for different filtration superficial velocities. The higher the filtration superficial velocity, the smaller the pressure drop percentage of the dust cake.

Fig. 10 presents the pressure drop across both filter system and dust cake while the operation condition transferred from fixed bed to dynamic bed at the filtration superficial velocity of $0.5 \mathrm{~m} \mathrm{~s}^{-1}$. It is found that they increase rapidly at the beginning stage and start to decline after about 50 minutes. Then the pressure drops remain almost constant when the filter changes into surface filtration stage after about 100 minutes. This indicates the essential ability of dynamic granular filters to maintain the cake thickness and pressure drop at a certain level without a blowback process. As a matter of fact, this characteristic of dynamic granular filters can improve collection efficiency and ensure appropriate system resistance. The variation of dust cake thickness with filtration time at the filtration superficial velocity of $0.5 \mathrm{~m} \mathrm{~s}^{-1}$ is illustrated in Fig. 11. As discussed before, the thickness of dust cake is difficult to exactly measure by experiment. In this study, the cake thickness is

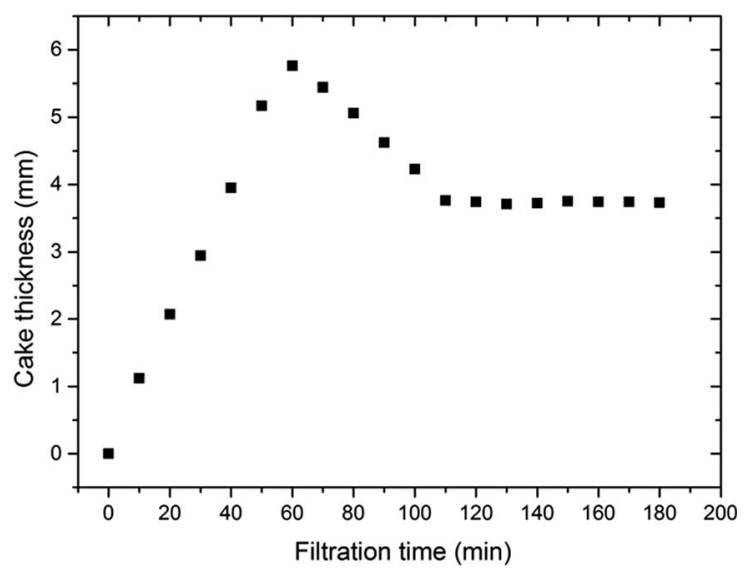

Fig. 11 Variation of cake thickness with filtration time, $U=0.5 \mathrm{~m} \mathrm{~s}^{-1}$.

calculated by the formulated equations, see eqn (5) and (6). From Fig. 10 and 11, it is noted that the trend of calculated cake thickness is very similar with that of pressure drop from experiments, which indicates that the proposed theoretical explanation regarding dust cake formation and formula derivations are applicable for the dynamic granular filter. In addition, it is found that there is an optimum thickness of dust cake around $3.8 \mathrm{~mm}$ in the studied case, at which the system resistance reaches a relatively lower level.

\section{Conclusions}

The optimum thickness of dust cake and the corresponding flow rate of granular material are the key factors for designing a dynamic granular filter, which could provide guarantee for excellent collection efficiency and appropriate system resistance. In this study, we extended our previous work to investigate the process of cake formation and growth on the performances of dynamic granular filters. The main conclusions can be summarized as follows:

(1) A new theoretical explanation for dust cake formation and growth has been proposed, by which the dust cake thickness and porosity can be calculated.

(2) The pressure drops of filter system and dust cake increase exponentially with increasing filtration superficial velocity. Therefore, although an increase of filtration superficial velocity could increase the processing amount of gas, it will consume more energy with lower collection efficiency. A balanced consideration should be given for dynamic granular filters in actual applications.

(3) With the progress in filtration time, the pressure drops across filter system and dust cake thickness increases rapidly at the beginning and decrease after about 50 minutes. Finally, they remain at a lower level when the filter changes into surface filtration stage. This characteristic of dynamic granular filters could improve the filtration efficiency and ensure an appropriate system resistance.

(4) The percentage of pressure drop across dust cake increases with filtration time but decreases with the increasing filtration superficial velocity. There is an optimum thickness of dust cake for dynamic granular filters, which is a critical factor providing guarantee for excellent collection efficiency at an appropriate filter system resistance.

\section{Conflicts of interest}

There are no conflicts to declare.

\section{Abbreviation}

St
$C_{\mathrm{m}}$
$d_{\mathrm{m}}$
$d_{\mathrm{p}}$
$d_{\mathrm{P}}$ $\mathrm{Pe}$

\author{
Stokes number \\ Cunningham's correction factor \\ Average diameter of filter medium \\ Average diameter of dust particulate \\ Pressure gradient \\ The Peclet number
}




$\begin{array}{ll}K & \text { Boltzmann constant } \\ T & \text { Absolute temperature } \\ L & \text { Average thickness of cake } \\ U & \text { Filtration superficial velocity } \\ \Delta P_{\mathrm{F}} & \text { Pressure drop across granular } \\ \Delta P_{\mathrm{C}} & \text { Pressure drop across dust cake } \\ P_{\text {in } n} & \text { Pressure value of inlet } \\ P_{\text {out } n} & \text { Pressure value of outlet } \\ \mu & \text { Gas viscosity } \\ \varepsilon & \text { Cake porosity } \\ \rho_{\mathrm{p}} & \text { Dust particle density } \\ \rho_{\mathrm{g}} & \text { Gas density } \\ \Delta P & \text { Pressure drop } \\ Q & \text { Mass flow rate } \\ t & \text { Filtration time } \\ M & \text { Mass of dust cake }\end{array}$

\section{Acknowledgements}

This study is supported by the China Postdoctoral Science Foundation (Grant No. 2017M610770) and the Fundamental Research Funds for the Central Universities (Grant No. FRF-BD18-015A).

\section{References}

1 Y. Fang, D. L. Mauzerall, J. Liu, A. M. Fiore and L. W. Horowitz, Clim. Change, 2013, 121, 239-253.

2 F. Li and L.-S. Fan, Energy Environ. Sci., 2008, 1, 248-267.

3 Prabhansu, M. K. Karmakar, P. Chandra and P. K. Chatterjee, J. Environ. Chem. Eng., 2015, 3, 689-702.

4 C. J. Tsai, D. R. Chen, H. Chein, S. C. Chen, J. L. Roth, Y. D. Hsu, W. Li and P. Biswas, J. Aerosol Sci., 2004, 35, 1105-1118.

5 L. Breedveld, G. Timellini, G. Casoni, A. Fregni and G. Busani, J. Cleaner Prod., 2007, 15, 86-93.

6 N. P. Cheremisinoff, Pollution Control Handbook for Oil and Gas Engineering, John Wiley \& Sons, Inc., 2016.

7 X. Li, Y. Hu, W. Zhang, M. Chen and Q. Li, J. Cent. South Univ., 2013, 44, 862-866.

8 P. V. Aravind and W. D. Jong, Prog. Energy Combust. Sci., 2012, 38, 737-764.

9 Y.-S. Chen, S.-S. Hsiau, S.-C. Lai, Y.-P. Chyou, H.-Y. Li and C.-J. Hsu, J. Hazard. Mater., 2009, 171, 987-994.
10 Y.-S. Chen, C.-J. Hsu, S.-S. Hsiau and S.-M. Ma, Energy, 2017, 120, 441-449.

11 G. Xiao, X. Wang, J. Zhang, M. Ni, X. Gao, Z. Luo and K. Cen, Powder Technol., 2013, 244, 93-99.

12 G. Xiao, X. Wang, J. Zhang, M. Ni, X. Gao, Z. Luo and K. Cen, Powder Technol., 2013, 244, 93-99.

13 Y.-Q. Zhang, P. Liang, J. Yu, J.-L. Zhu and X.-Z. Qin, RSC Adv., 2017, 7, 20266-20272.

14 Y.-S. Chen and S.-S. Hsiau, Powder Technol., 2009, 192, 217224.

15 I. Rodon, K. C. Lee, R. Pfeffer, A. M. Squires and O. K. Sønju, Powder Technol., 2005, 155, 52-61.

16 A. Y. Al-Otoom, Atmos. Environ., 2005, 39, 51-57.

17 Y. S. Chen and S. S. Hsiau, Chem. Eng. Process. Process Intensif., 2009, 48, 988-996.

18 Z. Qin and R. H. Pletcher, Adv. Powder Technol., 2015, 26, 4955.

19 W. Hoeflinger, H. Rud and G. Mauschitz, Sep. Purif. Technol., 2007, 58, 256-261.

20 K. J. Jeon and Y. W. Jung, Powder Technol., 2004, 141, 1-11.

21 J. J. Kim, R. Kased and T. Singh, Optim. Control Appl. Methods, 2004, 29, 257-277.

22 J. H. Choi, S. J. Ha and H. J. Jang, Powder Technol., 2004, 140, 106-115.

23 E. Schmidt, Filtr. Sep., 1997, 34, 365-368.

24 B. Liu, W. Zhou, P. Tan, X. Shan and Q. Yang, Powder Technol., 2016, 301, 387-395.

25 G. Yang and J. Zhou, J. China Univ. Min. Technol., 2007, 17, 201-204.

26 J. C. Bai, S. Y. Wu, A. S. Lee and C. Y. Chu, J. Hazard. Mater., 2007, 142, 324-331.

27 C. Grassi and L. Tognotti, Particulate Matter (PM), Springer Netherlands, 2008.

28 E. Gal, G. Tardos and R. Pfeffer, AlChE J., 1985, 31, 10931104.

29 R. C. Brown, H. Shi, G. Colver and S. C. Soo, Powder Technol., 2003, 138, 201-210.

30 P. V. Suresh and S. Jayanti, Environ. Sci. Pollut. Res., 2016, 111.

31 S. Ergun, Chem. Eng. Prog., 1952, 48, 89-94.

32 J. Smid, Y. P. Chyou and S. S. Hsiau, Powder Technol., 2010, 203, 288-297. 